\title{
PENGARUH UPAH MINIMUM DAN INFLASI TERHADAP JUMLAH PENDUDUK MISKIN DI PROVINSI JAMBI
}

\author{
Sudirman $^{1}$, Lili Andriani ${ }^{2}$
}

\begin{abstract}
Determination of the Minimum wage is based on the necessities of life are worthy(KHL) with attention to productivity and economic growth, while inflation where a situation where price levels are continuously increasing. While the problem of povertyis a classic problem because all countries had a huge poor population. Therefore need to look for a solution to overcome the problem of poverty. This research aims to find out how inflation, the minimum wage can be explained against the poor population in the province of Jambi province Year 2001-2015. This research is quantitative research using time series data). Types of data used in this research is secondary data obtained from the Central Bureau of statistics (BPS) province of Jambi and journals as a supporter. Multiple linear regression analysis of that minimum wages have a negative relationship toward the poor population in the province of Jambi where if the minimum wage goes up 1\% then the number of poor population will be down by0.410 and significantly on (a) 5\%, and in variables Inflation positive relationship towards the Poor population of Jambi province, if inflation rises $1 \%$ then the number ofpoor population will rise of 0.011 and insignificant on a (a) 5\%. As for the analysis of the test of the $F$ and t tests can noted that the influence of the free variable (Minimum wage and inflation) against the number of poor population in the province of Jambi simultaneously or together (FR $F)$ effect on the number of poor population. The value of Fhitung and Ftabel (51.194 $>3.89$ ), with significant extent $0.000<0.05$ then there are significant positive influence. for test $t$ of a variable minimum wage in the get the value of Thitung with the Ttabel of $7.373>2.179$.

Keywords: minimum wage, inflation
\end{abstract}

\section{PENDAHULUAN}

Kemiskinan merupakan masalah kompleks yang dipengaruhi oleh berbagai faktor yang saling berkaitan, antara lain tingkat pendapatan masyarakat, pengangguran, kesehatan, pendidikan, akses terhadap barang dan jasa, lokasi, geografis, dan lingkungan. Menurut Emil Salim Kemiskinan adalah suatu keadaan dimana manusia atau penduduk tidak dapat memenuhi kebutuhan pokok dan mereka dikatakan berada dibawah garis kemiskinan apabila pendapatan tidak cukup untuk memenuhi kebutuhan yang paling pokok ( Zakaria , 2009:94 ).

Permasalahan kemiskinan merupakan masalah yang kompleks dan bersifat multidimensional, oleh karena itu, upaya pengentasan kemiskinan harus dilakukan secara komprehensif, mencakup berbagai aspek kehidupan masyarakat, dan dilaksanakan secara terpadu ( Nasir, 2010:210 ). Upaya penanggulangan kemiskinan di Provinsi Jambi dilaksanakan dengan berbagai kebijakan untuk

${ }^{1}$ Dosen Fakultas Ekonomi Universitas Batanghari

${ }^{2}$ Dosen Fakultas Ekonomi Universitas Batanghari 
mengurangi/mengatasi kemiskinan melalui pemberdayaan masyarakat dengan Program Nasional Pemberdayaan Masyarakat ( PNPM ) Mandiri Perkotaan, Usaha Kecil dan Mikro. Hal tersebut dilakukan dengan memberikan pelatihan kepada masyarakat dan memberikan modal usaha kepada masyarakat yang ingin mendirikan usaha.

Kemiskinan dapat dilihat dari tingkat pendapatannya untuk memenuhi kebutuhan. Dengan demikian, tingkat pendapatan minimum merupakan pembatas antara keadaan yang disebut miskin atau sering disebut dengan istilah garis kemiskinan. Seseorang termasuk golongan miskin apabila hasil pendapatannya berada di bawah garis kemiskinan tidak cukup untuk memenuhi kebutuhan hidup minimum ( Sumodiningrat dalam Nurhayati,2007:225).

Berdasarkan Peraturan Menteri Tenaga Kerja Nomor : Per-01/Men/1999, Upah minimum adalah upah bulanan terendah yang terdiri dari upah pokok termasuk tunjangan tetap. Yang dimaksud dengan tunjangan tetap adalah suatu jumlah imbalan yang diterima pekerja secara tetap dan teratur pembayarannya, yang tidak dikaitkan dengan kehadiran ataupun pencapaian prestasi tertentu. Kebijakan penetapan upah minimum oleh pemerintah adalah kebijakan yang diterapkan dengan tujuan sebagai jaring pengaman terhadap pekerja atau buruh agar tidak diekspolitasi dalam bekerja dan mendapat upah yang dapat memenuhi kebutuhan hidup minimum (KHM). Jika kebutuhan hidup minimum dapat terpenuhi, maka kesejahteraan pekerja meningkatkan dan terbebas dari masalah kemiskinan.

Selain upah minimum provinsi, ada hal lain yang dapat mempengaruhi jumlah penduduk miskin yaitu inflasi. Inflasi bagi kelompok pendapatan rendah akan mengalami penurunan daya beli uang yang dimiliki untuk membeli kebutuhan seharihari. Uang yang dimiliki akan mengalami penurunan daya beli sehingga secara riil pendapatan orang tersebut akan mengalami penurunan seiring kenaikan inflasi (Arsyad,1999:342).

Tabel 1. Persentase Penduduk Miskin Provinsi Jambi Tahun 2001-2015

\begin{tabular}{cc} 
Tahun & Penduduk Miskin (\%) \\
\cline { 2 - 2 } 2001 & 19,71 \\
2002 & 13,18 \\
2003 & 12,74 \\
2004 & 12,45 \\
2005 & 11,88 \\
2006 & 11,37 \\
2007 & 10,27 \\
2008 & 9,32 \\
2009 & 8,77 \\
2010 & 8,34 \\
2011 & 8,65 \\
2012 & 8,42 \\
2013 & 8,27 \\
2014 & 7,98 \\
2015 & 7,72 \\
\hline
\end{tabular}

Sumber:BPS Provinsi Jambi 2016 
Dalam hal ini Provinsi Jambi berdasarkan data Badan Pusat Statistik (BPS) yang digambarkan pada tabel 01 persentase penduduk miskin Provinsi Jambi setiap tahunnya berkurang. Dalam tabel di atas persentase penduduk miskin tertinggi pada tahun 2001 sebesar 19,71. Sedangkan persentase penduduk miskin terendah terjadi pada tahun 2015. Persentase penduduk miskin setiap tahunnya menurun.

Upah minimum provinsi jambi dapat dikatakan masih rendah dibandingkan provinsi - provinsi lain . Setiap tahunnya mengalami peningkatan tetapi belum mencukupi standar kebutuhan hidup layak. Dengan pendapatan yang didapatkan , masyarakat membelanjakan untuk membeli barang-barang kebutuhan. Jika hargaharga barang tidak stabil/mengalami kenaikan dalam jangka waktu tertentu , tentunya akan membatasi masyarakat untuk membeli kebutuhannya.Berikut tabel 02 yang menjelaskan perkembangan upah minimum dan laju inflasi Provinsi Jambi tahun 2001-2015.

Tabel 2. Perkembangan Upah Minimum dan Laju Infasi di Provinsi Jambi tahun 2001-2015

\begin{tabular}{ccc}
\hline Tahun & Upah Minimumn (Rp) & Laju Inflasi ( \% ) \\
\hline 2001 & 245.000 & 10,11 \\
2002 & 304.000 & 6,25 \\
2003 & 390.000 & 3,79 \\
2004 & 425.000 & 7,25 \\
2005 & 485.000 & 6,6 \\
2006 & 563.000 & 10,66 \\
2007 & 658.000 & 7,42 \\
2008 & 724.000 & 11,57 \\
2009 & 800.000 & 2,9 \\
2010 & 900.000 & 2,40 \\
2011 & 1.028 .000 & 2,76 \\
2012 & 1.142 .500 & 4,22 \\
2013 & 1.300 .000 & 4,50 \\
2014 & 1.502 .230 & 2,89 \\
2015 & 1.710 .000 & 1,37 \\
\hline
\end{tabular}

Sumber:BPS Provinsi Jambi tahun 2016

Berdasarkan uraian pada latar belakang penelitian diatas, maka peneliti tertarik untuk melakukan penelitian dengan judul " Pengaruh Upah Minimum dan Inflasi Terhadap Jumlah Penduduk Miskin di Provinsi Jambi Periode 2001-2015”.

Berdasarkan latar belakang yang dikemukakan dalam penelitian ini, rumusan masalah yang ingin dikemukakan adalah sebagai berikut : Bagaimana pengaruh upah minimum dan inflasi terhadap jumlah penduduk miskin di Provinsi Jambi tahun 2001-2015 , Serta Variabel mana yang mempunyai pengaruh lebih besar terhadap jumlah penduduk miskin di Provinsi Jambi tahun 2001-2015? 
Berdasarkan latar belakang dan rumusan masalah di atas maka tujuan yang akan dicapai dalam penelitian ini adalah : Menganalisis pengaruh upah minimum dan inflasi terhadap jumlah penduduk miskin di Provinsi Jambi Periode 2001-2015, dan juga Menganalisis variabel yang mempunyai pengaruh yang lebih besar terhadap jumlah penduduk miskin di Provinsi Jambi tahun 2001-2015.

\section{Kemiskinan}

\section{LANDASAN TEORI}

Kemiskinan adalah fenomena yang seringkali di jumpai dalam kehidupan bersosial. kemiskinan seringkali dipandang sebagai gejala rendahnya tingkat kesejahteraan semata padahal kemiskinan merupakan gejala yang bersifat kompleks dan multidimensi. Kemiskinan dapat didefinisikan sebagai suatu situasi atau kondisi yang dialami seseorang atau sekelompok orang yabg tidak mampu menyelenggarakan hidupnya sampai suatu taraf yang dianggap manusiawi (Bappenas,2002). Secara garis besar definisi miskin dapat dipilah menjadi dua aspek yaitu: (1)aspek primer,yaitu berupa miskin aset ( harta ),organisasi politik, pengetahuan dan keterampilan (2) aspek sekunder,yaitu berupa miskin terhadap jaringan sosial,sumber-sumber keuangan dan informasi ( Lincolin,2010:299 )

Menurut Ravallion (2010;299) kemiskinan adalah kelaparan, tidak memiliki tempat tinggal, bila sakit tidak mempunyai dana untuk berobat. Orang miskin umumnya tidak dapat membaca karena tidak mampu bersekolah, tidak memiliki pekerjaan, takut menghadapi masa depan, kehilangan anak karena anak sakit. Kemiskinan adalah ketidakberdayaan, terpinggirkan dan tidak memiliki rasa bebas.

\section{Upah Minimum}

Upah Minimum Provinsi ( UMP ) adalah upah minimum yang berlaku untuk seluruh kabupaten/kota di satu provinsi. Dahulu Upah Minimum Provinsi dikenal dengan istilah Upah Minimum Regional Tingkat I. Dasar hukum penetapan UMP adalah Peraturan Menteri Tenaga Kerja dan Transmigrasi Nomor 7 Tahun 2013 tentang Upah Minimum. UMP ditetapkan oleh gubernur dengan memperhatikan rekomendasi Dewan Pengupahan Provinsi ( Bappeda Provinsi Jambi ).Penetapan upah dilaksanakan setiap tahun melalui proses yang panjang. Mula-mula Dewan Pengupahan Daerah (DPD) yang terdiri dari birokrat, akademisi, buruh danpengusaha mengadakan rapat, membentuk tim survei dan turun ke lapangan mencari tahu harga sejumlah kebutuhan yang dibutuhkan oleh pegawai, karyawan dan buruh. Setelah survei di sejumlah kota dalam provinsi tersebut yang dianggap representatif, diperoleh angka Kebutuhan Hidup Layak (KHL) - dulu disebut Kebutuhan Hidup Minimum (KHM). Berdasarkan KHL, DPD mengusulkan upah minimum regional (UMR) kepada Gubernur untuk disahkan. Komponen kebutuhan hidup layak digunakan sebagai dasar penentuan upah minimum berdasarkan kebutuhan hidup pekerja lajang (belum menikah).

Dalam pasar tenaga kerja sangat penting untuk menetapkan besarnya upah yang harus dibayarkan perusahaan pada pekerjanya. Undang-undang upah minimum menetapkan harga terendah tenaga kerja yang harus dibayarkan (Mankiw, 2006:223). 


\section{Inflasi}

Menurut Nopirin (2000:104) mengungkapkan bahwa Inflasi ialah suatu proses dari suatu kenaikan harga pada umumnya dan akan bergerak secara terus-menerus, misalnya pada barang-barang primer kebutuhan sehari-hari.

Inflasi adalah kecenderungan dari harga-harga untuk menaik secara umum dan terus menerus. Kenaikan harga dari satu atau dua barang saja tidak disebut inflasi, kecuali bila kenaikan tersebut meluas kepada (atau mengakibatkan kenaikan) sebagian besar dari harga barang-barang lain ( Samuelson,2004:98).

Inflasi sebagai suatu kecenderungan meningkatnya tingkat harga umum secara terus menerus sepanjang waktu (a sustained tedency for the general level of prices to rise over time) ( Venieris dan Seblod:1978). Sedangkan Pengertian inflasi menurut (Boediono; 1982) inflasi adalah Kecenderungan harga- harga naik secara umum dan terus menerus, kenaikan harga dari satu atau dua barang saja tidak disebut inflasi kecuali kenaikan tersebut meluas kepada (atau mengakibatkan kenaikan) sebagian besar dari harga- harga barang lain. Dalam praktek, inflasi dapat diamati dengan mengamati gerak dari indek harga. Tetapi di sini harus diperhitungkan ada tidaknya suppressed inflation (inflasi yang ditutupi) Akibat inflasi secara umum adalah menurunnya daya beli masyarakat karena secara riel tingkat pendapatannya juga menurun. Jadi, misalkan besarnya inflasi pada tahun yang bersangkutan naik sebesar 5\% sementara pendapatan tetap, maka itu berarti secara riel pendapatan mengalami penurunan sebesar $5 \%$ yang akibatnya relatif akan menurunkan daya beli sebesar 5\% juga, ( Lincolin 2002: 254).

\section{METODE PENELITIAN}

Metode analisis yang digunakan pada penelitian ini adalah dengan metode analisis regresi linier berganda dengan pendekatan Ordinary Least Square (OLS). Alat analisis yang digunakan dalam penelitian ini adalah SPSS 23. Dalam menganalisis faktor-faktor yang mempengaruhi kemiskinan di Provinsi Jambi, digunakan model :

$\mathrm{Y}=\beta 0+\beta 1 \mathrm{X} 1+\beta 2 \mathrm{X} 2+\mu 1$

Dimana:

Y : Kemiskinan

$\mathrm{X} 1$ : Upah Minimum

X2 : Inflasi

$\beta 0$ : Konstanta

$\beta 1$ : Koefisien Upah Minimum

$\beta 2$ : Koefisien Inflasi

$\mu 1$ : Faktor Pengganggu

Persamaan regresi linear berganda sebagai berikut:

$Y^{\prime}=a+b_{1} X_{1}+b_{2} X_{2}+\ldots . .+b_{n} X_{n}$

Untuk mengetahui derajat kepekaan Kemiskinan terhadap faktor - faktor yang mempengaruhinya, digunakan konsep elastisitas. Besarnya nilai elastisitas dalam 
model ini dapat diketahui langsung besarnya nilai koefisien regresi variabel-variabel penduganya ( Gujarati, 1995 ).

\section{Deteksi Penyimpangan Terhadap Asumsi Klasik}

Sebelum melakukan interpretasi terhadap hasil regresi dari model yang digunakan, terlebih dahulu dilakukan pengujian terhadap asumsi-asumsi klasik model OLS, sehingga model tersebut layak digunakan. Tujuannya agar diperoleh penaksiran yang bersifat Best Linier Unbiased Estimator (BLUE). Pengujian ini dimaksudkan untuk mendeteksi ada tidaknya multikolinearitas, heterokedastisitas dan autokolerasi pada hasil estimasi, karena apabila terjadi penyimpangan maka uji t dan uji F yang dilakukan sebelumnya menjadi tidak valid.

\section{Deteksi Multikolinearitas}

Istilah multikolinearitas berkenaan dengan terdapatnya lebih dari satu hubungan linear pasti dan istilah kolinearitas berkenaan dengan terdapatnya satuhubungan linear. Pembedaan ini jarang diperhatikan dalam praktek, dan multikolinearitas berkenaan dengan kedua kasus tadi. Multikolineritas dalam penelitian ini dideteksi dengan menggunakan Auxilliary Regression yaitu dengan membandingkan besar nilai R2 model utama dengan R2 variabel - variabel independennya secara partial. Jika R2 model utama lebih besar daripada R2 variabel-variabel independennya maka tidak terjadi multikolinearitas (Gujarati, 1995).

\section{Deteksi Autokorelasi}

Auto korelasi adalah suatu keadaan dimana kesalahan penggangguan dari periode tertentu $(\mu \mathrm{t})$ berkorelasi dengan kesalahan pengganggu dari periode sebelumnya ( $\mu \mathrm{t}-1$ ). Pada kondisi ini kesalahan pengganggu tidak bebas tetapi satu sama lain saling berhubungan.nmendeteksi ada atau tidaknya autokorelasi dapat menggunakan Uji Langrange Multiplier (LM Test). Dalam uji ini apabila nilai probabilitas dari R2 tidak signifikan $(<0,05)$, maka dapat disimpulkan autokorelasi (Insukindro, 2004).

\section{Deteksi Heterokedasitas}

Uji heterokedastisitas bertujuan untuk menguji apakah dalam model regresi terjadi ketidaksamaan varian dari residual suatu pengamatan ke pengamatan yang lain. Heterokedastisitas terjadi apabila variabel gangguan tidak mempunyai varian yang sama untuk semua observasi. Akibat adanya heterokedastisitas, penaksir OLS tidak bias tetapi tidak efisien. Jika nilaiObs*Rsquared lebih kecil daripada c tabel maka tidak ada heterokesdasitas pada model (Gujarati, 1995).

\section{Deteksi Normalitas}

Deteksi normalitas bertujuan untuk menguji apakah dalam model regresi,variabel pengganggu memiliki distribusi normal atau tidak. Dalam penelitian ini, untuk menguji apakah distribusi data normal atau tidak digunakan uji Jaque-Bera atau J-B Test membandingkan antara nilai J-B ( $\chi 2$ hitung) terhadap $\chi 2$ tabel (Chi-Square). Rumus yang digunakan (Insukindro, 2004) adalah: JB = (N$\mathrm{k}) / 6$. [S2 + (K-3)2]........

\section{Pengujian Hipotesis}

Uji signifikansi merupakan prosedur yang digunakan untuk menguji kebenaran atau kesalahan dari hasil hipotesis nol dari sampel. Ide dasar yang melatar belakangi pengujian signifikansi adalah uji statistik (estimator) dari 
distribusi sampel dari suatu statistik di bawah hipotesis nol. Keputusan untuk mengolah $\mathrm{H} 0$ dibuat berdasarkan nilai uji statistik yang diperoleh dari data yang ada (Gujarati,1995).

\section{Koefisisen Determinasi (R2)}

Koefisien deteminasi (R2) merupakan angka yang memberikan proporsi atau persentase variasi total dalam variabel tak bebas (Y) yang dijelaskan oleh variabel bebas (X) (Gujarati, 2003). Koefisien determinasi dirumuskan sebagai berikut :

$$
\mathrm{R} 2=\frac{\sum(\hat{\mathrm{Y}} \mathrm{i}-\overline{\mathrm{Y}}) 2}{\sum(\mathrm{Yi}-\overline{\mathrm{Y}}) 2}
$$

(Imam Ghozali, 267:2005).

\section{Uji Signifikansi Simultan (Uji F)}

Uji F digunakan untuk menunjukan apakah keseluruhan variabel independen berpengaruh terhadap variabel dependen. Perumusan hipotesisnya adalah sebgai berikut (Gujarati, 2003) Rumus yang digunakan dalam Uji F ini adalah sebagai berikut:

$$
\begin{gathered}
\mathrm{F} \text { hitung }=\underline{\mathrm{R} 2 /(\mathrm{k}-1)} \\
(1-\mathrm{R} 2) /(\mathrm{n}-\mathrm{k})
\end{gathered}
$$

\section{Uji Signifikansi Parameter (Uji t)}

Uji statistik t dilakukan untuk menunjukan seberapa jauh pengaruh satu variabel penjelas atău independen secara individual dalam menerangkan variasi varabel dependen (Ghozali, 2005).: $\mathrm{t}=\beta$. (3.5 Se $(\beta i)$

\section{HASIL PENELITIAN}

Analisis ini untuk mengetahui arah hubungan antara variabel independen dengan variabel dependen apakah positif atau negatif dan untuk memprediksi nilai dari variabe dependen apabila independen mengalami kenaikan atau penurunan. Berikut hasil uji regresi dengan menggunakan program SPSS.

Tabel 3. Hasil Analisis Regresi Linear Berganda Coefficients $^{\mathrm{a}}$

\begin{tabular}{llrrrrrrr}
\hline & & \multicolumn{2}{c}{$\begin{array}{c}\text { Unstandardized } \\
\text { Coefficients }\end{array}$} & \multicolumn{2}{c}{$\begin{array}{c}\text { Standardized } \\
\text { Coefficients }\end{array}$} & \multicolumn{3}{c}{ Collinearity } \\
Model & & \multicolumn{1}{c}{ S } & Std. Error & Beta & \multicolumn{1}{c}{ t } & Sig. & Tolerance & VIF \\
\hline 1 & (Constant) & 3,401 &, 350 & & 9,714 &, 000 & & \\
& Upah &,- 410 &, 056 &,- 928 & $-7,373$ &, 000 &, 552 & 1,810 \\
& Inflasi &, 011 &, 052 &, 027 &, 218 &, 831 &, 552 & 1,810 \\
\hline
\end{tabular}

a. Dependent Variable: JP.Miskin

$$
Y=3,401-0,410 X_{1}+0,011 X_{2}
$$
berikut:

Dari persamaan regresi linear tersebut dapat diinterpresentasikan sebagai

Nilai Konstanta sebesar 3,401 memberikan arti bahwa apabila Upah Minimum 
$\left(\mathrm{X}_{1}\right)$, Inflasi $\left(\mathrm{X}_{2}\right)$. Diasumsikan $=0$, maka Jumlah Penduduk Miskin Provinsi Jambi secara konstan bernilai sebesar 3,401. Nilai koefisien regresi variabel Upah Minimum $\left(\mathrm{X}_{1}\right)$ sebesar -0,410 dapat diartikan jika Upah Minimum naik 1 persen maka Jumlah Penduduk Miskin akan turun sebesar 0,410. Nilai Koefisien regresi variabel Inflasi $\left(\mathrm{X}_{2}\right)$ sebesar 0,011 dapat diartikan jika Inflasi naik 1 persen maka Jumlah Penduduk Miskin akan naik 1 persen sebesar 0,011.

Deteksi Penyimpangan Asumsi Klasik Deteksi Multikolinearitas

\begin{tabular}{|c|c|c|c|c|c|c|c|c|}
\hline \multirow[b]{3}{*}{ Model } & \multicolumn{8}{|c|}{$\begin{array}{l}\text { Tabel 4. Uji Multikolinearitas } \\
\text { Coefficients }^{\mathrm{a}}\end{array}$} \\
\hline & & \multicolumn{2}{|c|}{$\begin{array}{l}\text { Unstandardized } \\
\text { Coefficients }\end{array}$} & \multirow{2}{*}{$\begin{array}{c}\text { Standardized } \\
\text { Coefficients } \\
\text { Beta }\end{array}$} & \multirow[b]{2}{*}{2} & \multirow[b]{2}{*}{ Sig. } & \multicolumn{2}{|c|}{$\begin{array}{l}\text { Collinearity } \\
\text { Statistics }\end{array}$} \\
\hline & & B & Std. Error & & & & Tolerance & VIF \\
\hline 1 & (Constant) & 3,401 & ,350 & & 9,714 &, 000 & & \\
\hline & Upah &,- 410 & 056 &,- 928 & $-7,373$ & ,000 & ,552 & 1,810 \\
\hline & Inflasi &, 011 & ,052 &, 027 & ,218 & ,831 & ,552 & 1,810 \\
\hline
\end{tabular}

a. Dependent Variable: JP.Miskin

Sesuai dengan ketentuan uji multikolinieritas, jika nilai VIF kurang dari 10 maka tidak terdapat korelasi. Berdasarkan tabel di atas dapat dilihat bahwa nilai VIF yaitu 1,810 untuk variabel ( X1 ) dan nilai VIF untuk ( X2) yaitu 1,810 kurang dari 10. Sehingga dapat disimpulkan bahwa tidak terdapat multikolinieritas dalam data penelitian ini. Artinya bahwa antara variabel bebas Jumlah Penduduk Miskin (X1), Upah Minimum (X2) dan Inflasi ( X2 ) tidak saling mengganggu atau mempengaruhi. Deteksi Autokorelasi

Uji Autokorelasi merupakan pengujian yang dilakukan untuk menguji ada tidaknya pengaruh antara variabel penganggu dalam masing masing variabel bebas. Dalam penelitian ini uji autokorelasi menggunakan tes Durbin Watson dengan ketentuan sebagai berikut: $\mathrm{dW}<\mathrm{dL}$, berarti ada autokorelasi positif $(+) \mathrm{dL}<\mathrm{dW}<$ $\mathrm{dU}$, tidak dapat disimpulkan $\mathrm{dU}<\mathrm{dW}<4$-dU, berarti tidak terjadi autokorelasi. 4-dU $<\mathrm{dW}<4$-dL, tidak dapat disimpulkan $\mathrm{dW}>4$-dL, berarti ada autokorelasi negatif (-) Dengan jumlah sampel $\mathrm{n}=15, \alpha=0,05$ dan banyaknya variabel independent $\mathrm{k}=2$, maka di dapat nilai kritis $\mathrm{dL}=0,9455$ dan $\mathrm{dU}=1,5432$. Hasil pengujian uji autokorelasi dalam penelitian ini menggukan spss 23 dengan hasil sebagai berikut:

\begin{tabular}{|c|c|c|c|c|c|}
\hline \multicolumn{6}{|c|}{$\begin{array}{l}\text { Tabel 5. Uji Autokorelasi } \\
\text { Model Summary }\end{array}$} \\
\hline Model & $\mathrm{R}$ & R Square & $\begin{array}{l}\text { Adjusted R } \\
\text { Square }\end{array}$ & $\begin{array}{l}\text { Std. Error of } \\
\text { the Estimate }\end{array}$ & $\begin{array}{l}\text { Durbin- } \\
\text { Watson }\end{array}$ \\
\hline 1 & $946^{\mathrm{a}}$ & 895 & 878 &, 03939 & 1,184 \\
\hline
\end{tabular}


Berdasarkan tabel tersebut dapat diketahui nilai Durbin watson sebesar 1,201. Sehingga nilai DW berada diantara dU (1,5432) > DW $(1,201)<4-\mathrm{dU}(4-1,5432$ $=2,4568$ ). Maka dapat disimpulkan bahwa dalam penelitian ini tidak terdapat autokorelasi. Artinya bahan variabel independent dalam penelitian ini tidak terganggu atau terpengaruhi oleh variabel penggangu.

\section{Deteksi Heterokedasitas}

\section{Grafik 1 Uji Heterokedasitas}

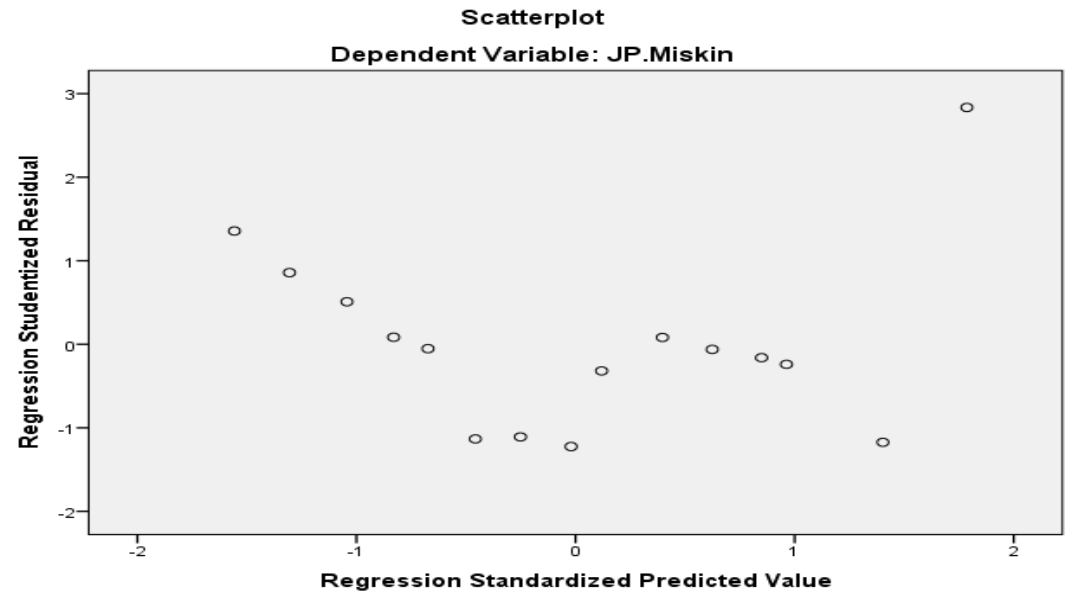

Dasar analisis uji heteroskodesitas dengan grafik plot adalah jika titik dalam grafik tersebar (tidak membentuk pola) maka tidak terjadi heteroskodesitas. Berdasarkan gambar tersebut dapat dilihat bahwa titik-titik yang ada tidak membentuk pola yang teratur. Sehingga dapat disimpulkan bahwa pada data dalam penelitian ini tidak terjadi heteroskodesitas. Artunya dalam fungsi regresi di penelitian ini tidak muncul gangguan karena varian yang tidak sama.

\section{Deteksi Normalitas}

Uji normalitas dilakukan untuk mengetahui apakah data yang diambil dalam penelitian berasal dari populasi yang berdistribusi normal atau tidak. Pengujian normalitas dalam penelitian ini yaitu melalui normal probability plot dengan menggunakan SPSS 23 dan diperoleh hasil sebagai berikut:

\section{Grafik 2}

\section{Uji Normalitas}

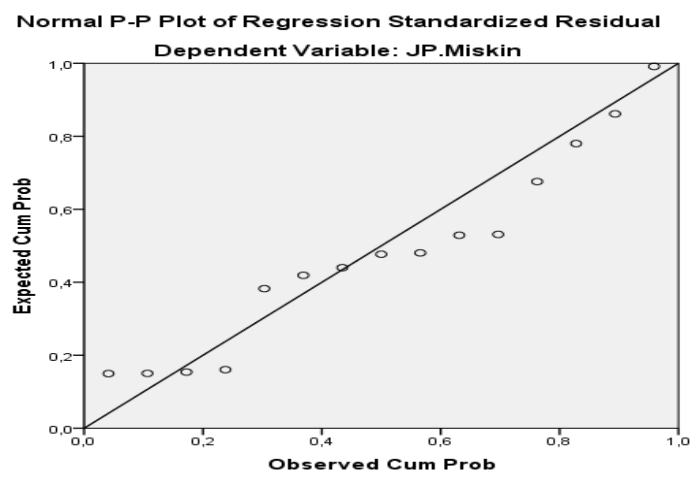


Uji normalitas dengan normal probability plot mensyaratkan bahwa penyebaran data harus berada disekitar wilayah garis diagonal dan mengikuti arah garis diagonal. Berdasarkan gambar di atas dapat disimpulkan bahwa data dalam penelitian ini memenuhi syarat normal probability plot sehingga model regresi dalam penelitian memenuhi asumsi normalitas ( berditribusi normal ). Artinya data dalam penelitian ini berasal dari populasi yang berdistribusi normal.

\section{Pengujian Hipotesis}

\section{Koefisien Determinasi ( $\mathbf{R}^{2}$ )}

Variabel Upah dan inflasi belum dikeluarkan, dihasilkan R (Koefisien Korelasi) sebesar 0,878 yang menunjukkan pengaruh yang sangat kuat. Koefisien determinasi sebesar 0,895 bearti variasi besar kecinya produktivitas yang dihasilkan dapat diterangkan oleh adanya variasi variabel-variabel bebas sebesar 87,8 \% dan $12,2 \%$.

\section{Uji Statistik Simultan (F)}

Tabel 6: Hasil Uji Statistik Simultan F ANOVA $^{\mathrm{a}}$

\begin{tabular}{|c|c|c|c|c|c|c|}
\hline \multicolumn{7}{|c|}{ 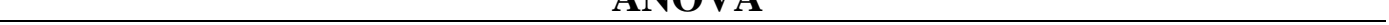 } \\
\hline Model & & $\begin{array}{l}\text { Sum of } \\
\text { Squares }\end{array}$ & $\mathrm{df}$ & Mean Square & $\mathrm{F}$ & Sig. \\
\hline 1 & Regression &, 159 & 2 &, 079 & 51,194 &, $000^{\mathrm{b}}$ \\
\hline & Residual & 019 & 12 & ,002 & & \\
\hline & Total & 177 & 14 & & & \\
\hline
\end{tabular}

a. Dependent Variable: JP.Miskin

b. Predictors: (Constant), Inflasi, Upah

Dari tabel 6 tersebut dapat dilihat bahwa nilai F hitung sebesar 51,194 dengan p-value sebesar 0,000 . Oleh karena nilai $\mathrm{F}$ hitung lebih besar dari nilai $\mathrm{F}$ tabel $(51,044>3,89)$, dengan taraf signifikan $0,000<0,05$ maka terdapat pengaruh positif yang signifikan antara variabel independen ( Upah Minimum dan Inflasi) secara simultan terhadap variabel dependen ( Jumlah Penduduk Miskin Provinsi Jambi) pada tingkat kepercayaan 95\%. Hasil tersebut menunjukkan bahwa hipotesis penelitian ini yaitu Upah Minimum dan inflasi, secara simultan berpengaruh terhadap Jumlah Penduduk Miskin di Provinsi Jambi.

\section{Uji Statistik Parsial (t)}

Uji ini digunakan untuk mengetahui apakah variabel independen (X) berpengaruh secara signifikan terhadap variabel dependen (Y). untuk mengetahui apakah pengaruh itu signifikan atau tidak adalah dengan membandingkan nilai $\mathrm{t}$ hitung dengan $\mathrm{t}$ tabel pada derajat signifikansi $5 \%(\mathrm{df1}=2 \mathrm{df} 2=12 \mathrm{t}$ tabel $=2,179)$. Hasil uji t terhadap variabel penelitian dengan menggunakan bantuan program SPSS 23 sebagai berikut : 


\begin{tabular}{|c|c|c|c|c|c|c|c|c|}
\hline \multicolumn{9}{|c|}{$\begin{array}{c}\text { Tabel 7: Hasil Uji Statistik t } \\
\text { Coefficients }^{\mathbf{a}}\end{array}$} \\
\hline \multirow[b]{2}{*}{ Model } & & \multicolumn{2}{|c|}{$\begin{array}{l}\text { Unstandardized } \\
\text { Coefficients }\end{array}$} & \multirow{2}{*}{$\begin{array}{l}\text { Standardized } \\
\text { Coefficients } \\
\text { Beta }\end{array}$} & \multirow[b]{2}{*}{$\mathrm{t}$} & \multirow[b]{2}{*}{ Sig. } & \multicolumn{2}{|c|}{$\begin{array}{l}\text { Collinearity } \\
\text { Statistics }\end{array}$} \\
\hline & & B & Std. Error & & & & Tolerance & VIF \\
\hline 1 & (Constant) & 3,401 &, 350 & & 9,714 &, 000 & & \\
\hline & Upah &,- 410 & 056 &,- 928 & $-7,373$ & ,000 & ,552 & 1,810 \\
\hline & Inflasi &, 011 & ,052 &, 027 & ,218 & ,831 &, 552 & 1,810 \\
\hline
\end{tabular}

a. Dependent Variable: JP.Miskin

Dari tabel 7 dapat dijelaskan sebagai berikut :

Nilai t hitung variabel Upah Minimum (X1) adalah sebesar 7,373 jika dibandingkan dengan $t$ tabel sebesar 2,179 maka 7,373 > 2,179. Level signifikan variabel Upah Minimum $\left(\mathrm{X}_{1}\right)$ adalah sebesar $0,000<(0,05)$, dengan demikian $\mathrm{H} 0$ ditolak dan H1 diterima. Dari hasil tersebut dapat disimpulkan bahwa secara parsial terdapat pengaruh yang signifikan antara Upah Minimum dengan Jumlah Penduduk Miskin di Provinsi Jambi. Pengujian koefisien regresi variabel Inflasi $\left(\mathrm{X}_{2}\right)$ Nilai $\mathrm{t}$ hitung variabel Inflasi $\left(\mathrm{X}_{2}\right)$ adalah sebesar 0,218 jika dibandingkan dengan $\mathrm{t}$ tabel sebesar 2,179 maka 0,218<2,179. Level signifikan variabel Inflasi $\left(\mathrm{X}_{2}\right)$ adalah sebesar $0,831>(0,05)$ dengan demikian $\mathrm{H} 0$ diterima dan $\mathrm{H} 1$ ditolak. Dari hasil tersebut dapat disimpulkan bahwa secara parsial tidak terdapat pengaruh yang signifikan antara Inflasi dengan Jumlah Penduduk Miskin di Provinsi Jambi.

\section{SIMPULAN}

Berdasarkan hasil penelitian dan pembahasan yang dilakukan untuk menganalisa perkembangan dan pengaruh upah minimum dan inflasi terhadap jumlah penduduk miskin di Provinsi Jambi pada tahun 2001-2015 maka dapat disimpulkan: Dari analisis regresi linear berganda bahwa upah minimum mempunyai hubungan negatif terhadap jumlah penduduk miskin di Provinsi Jambi dimana jika upah minimum naik $1 \%$ maka jumlah penduduk miskin akan turun sebesar 0,410 dan signifikan pada (a) 5\%, dan pada variabel Inflasi mempunyai hubungan positif terhadap Jumlah Penduduk Miskin Provinsi Jambi, jika inflasi naik 1\% maka jumlah penduduk miskin akan naik sebesar 0,011 dan tidak signifikan pada (a) 5\%. Sedangkan untuk analisis dari uji $\mathrm{F}$ dan uji t dapat diketahui bahwa pengaruh variabel bebas ( Upah Minimum dan Inflasi ) terhadap Jumlah Penduduk Miskin di Provinsi Jambi secara simultan atau bersama-sama ( Uji F ) berpengaruh terhadap jumlah penduduk miskin. Nilai Fhitung dan Ftabel $(51,194>3,89)$, dengan taraf signifikan $0,000<0,05$ maka terdapat pengaruh positif yang signifikan. Untuk uji t dari variabel upah minimum di dapatkan nilai Thitung dengan Ttabel sebesar 7,373 > 2,179. Level signifikan variabel Upah Minimum $\left(\mathrm{X}_{1}\right)$ adalah sebesar $0,000<(0,05)$ dan untuk uji $\mathrm{t}$ dari variabel inflasi sebesar $0,218<2,179$. Level signifikan variabel Inflasi $\left(\mathrm{X}_{2}\right)$ adalah sebesar 0,831> $(0,05)$. Berdasarkan analisis regresi berganda dengan SPSS 23 di dapat hasil bahwa variabel yang lebih besar mempengaruhi dalam penelitian ini adalah variabel Upah Minimum. Upah minimum dapat mempengaruhi jumlah penduduk miskin di Provinsi Jambi. Jika upah Minimum meningkat maka dapat 
menurunkan jumlah penduduk miskin di Provinsi Jambi karena dengan pendapatan yang diperoleh dari bekerja, mereka dapat memenuhi kebutuhan hidupnya. Semakin banyak pendapatan yang diperoleh maka semakin besar kesempatan untuk memenuhi kebutuhan hidup.

\section{DAFTAR PUSTAKA}

BPS Provinsi Jambi, 2016, Jambi Dalam Angka, Publikasi Tahunan Badan Pusat Statistik Provinsi Jambi tahun 2005-2016. Jambi

Amirul Hadi dan Haryono, 1998. Metodologi Penelitian Pendidikan, CV Pustaka Setia : Bandung

Arsyad, Lincolin, 2006, Ekonomi Daerah : Pengantar Perencanaan Pembangunan. Edisi Kedua. BPFE : Yogyakarta.

. 2005. Pengantar Perencanaan Pembangunan Ekonomi Daerah, Edisi Kedua. Yogyakarta: BPFE-Yogyakarta.

Boediono, 2000, Teori Pertumbuhan Ekonomi, Seri Sinopsis Pengantar Ilmu Ekonomi. Edisi 1, Cetakan Ke-5. BPFE : Yogyakarta.

Darise, Nurlan. 2007. Pengelolaan Keuangan Daerah. Jakarta: Indeks Pustaka.

Ghozali, Imam. 2005. Aplikasi Analisis Multivariate dengan Program SPSS. Semarang: UNDIP.

Mardiasmo. 2004. Otonomi dan Manajemen Keuangan Daerah. Yogyakarta: Andi Offset.

Nurcholis, Hanif. 2007. Teori dan Praktik, Pemerintahan dan Otonomi Daerah. Jakarta: Grasindo. 